\title{
Stimulating Mechanistic Reasoning in Physics Using Student-Constructed Stop-Motion Animations
}

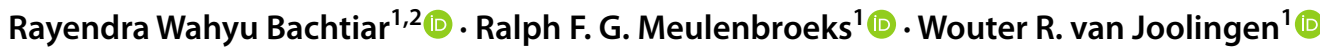

Accepted: 19 April 2021 / Published online: 28 April 2021

(c) The Author(s) 2021

\begin{abstract}
This article reports on a case study that aims to help students develop mechanistic reasoning through constructing a model based stop-motion animation of a physical phenomenon. Mechanistic reasoning is a valuable thinking strategy for students in trying to make sense of scientific phenomena. Ten ninth-grade students used stop-motion software to create an animation of projectile motion. Retrospective think-aloud interviews were conducted to investigate how the construction of a stopmotion animation induced the students' mechanistic reasoning. Mechanistic reasoning did occur while the students engaged in creating the animation, in particular chunking and sequencing. Moreover, all students eventually exhibited mechanistic reasoning including abstract concepts, e.g., not directly observable agents. Students who reached the highest level of mechanistic reasoning, i.e., chaining, demonstrated deeper conceptual understanding of content.
\end{abstract}

Keywords Mechanistic reasoning $\cdot$ Stop-motion animation $\cdot$ Modeling $\cdot$ Physics $\cdot$ Classical mechanics

\section{Introduction}

Mechanistic reasoning has been found to be a powerful thinking strategy for students trying to make sense of phenomena by explaining the processes underlying cause-effect relationships through involving causal agents, "entities," and their action, "what entities do" (Krist et al., 2019; Machamer et al., 2000; Russ et al., 2008). For example, considering the question "Why does an ice cube melt?", two hypothetical answers may be given by students:

Student A says that "heat makes an ice cube turn into liquid water"; student B states that "while heating an ice cube, water molecules are moving faster and they break the hydrogen bonds between molecules and eventually these molecules separate, thus forming liquid water."

Student A's statement conveys a particular cause (heat) and an effect (liquid water) without considering how the

Rayendra Wahyu Bachtiar

r.w.bachtiar@uu.nl

1 Freudenthal Institute for Science and Mathematics Education, Utrecht University, Utrecht, The Netherlands

2 Faculty of Teacher Training and Education, University of Jember, Jember, Indonesia cause brings about the effect. Student B's explanation provides processes underlying such causality through including a mechanism in terms of unobservable causal agents, entities (water molecules), and what these entities do (an activity), i.e., "moving faster" and "break hydrogen bonds," to enable the ice to become liquid water. This makes student B's explanation a mechanistic one.

A number of studies have demonstrated the value of mechanistic reasoning in promoting students' understanding of concepts (Bolger et al., 2012; Southard et al., 2016; Talanquer, 2018). For example, Southard et al. (2016) revealed that mechanistic reasoning was needed to understand molecular mechanisms in connecting genes to traits. Some studies consider mechanistic reasoning as a worthy thinking strategy for developing so-called "good" scientific explanations (Braaten \& Windschitl, 2011; de Andrade et al., 2019; Talanquer, 2010). Braaten and Windschitl (2011) defined good scientific explanations as explication, causation, or justification. Mechanistic explanations can provide such causation. A study by de Andrade et al. (2019) noticed that the students who involved unobservable agents, "particles of air," and the behavior of these particles, "move faster," were able to explain why an increase in the temperature of a gas effected an increase in the pressure of that gas.

However, incorporating relevant entities and how these entities engage in particular behavior to give rise to a phenomenon is reported to be especially difficult (de Andrade 
et al., 2019; Haskel-Ittah et al., 2019; Schwarz et al., 2014; Speth et al., 2014; Visintainer \& Linn, 2015). For example, Speth et al. (2014) noticed that students' explanations of evolution failed to incorporate molecular entities, such as DNA and genes, even after instruction, leading to nonmechanistic explanations. Another study documented that, even though the students were aware of human factors, as causal agents responsible for global climate change, their explanations failed to explain how the human action warmed the earth (Visintainer \& Linn, 2015). Schwarz et al. (2014) showed that, even though students recognized the existence of water molecules, their explanations of evaporation were still not mechanistic due to the absence of activities of these entities bringing about evaporation.

In view of the difficulty in promoting mechanistic reasoning, there is a need to support students in building such reasoning. In this study, we investigated one potential support: using the creation of stop-motion animations (SMA) as a modeling tool. By creating and ordering multiple images of a process and sequencing these in the correct order we contend "chunking and sequencing," the nature of SMA can be a support for students' mechanistic reasoning. To model a phenomenon using stop-motion animation, students need to construct a series of frames representing the underlying process of the phenomenon. Creating each frame requires thinking about a step in the process. When all frames are arranged in sequence, students need to think about a coherent story representing the underlying process of the phenomenon, thus leading to the use of mechanistic reasoning. The goal of this study is, therefore, to investigate how engaging the students in constructing a SMA induces their mechanistic reasoning. In particular, the present study focuses on answering the following research questions:

RQ1: to what extent are 9th grade students able to model a phenomenon in classical mechanics using stop-motion animation?

RQ2: to what extent do the students use mechanistic reasoning while discussing their stop-motion animations?

\section{Background}

\section{Computer-Based Modeling}

There has been considerable literature advocating learning science through creating models by drawing (Ainsworth et al., 2011; Bollen \& Joolingen, 2013, van Joolingen et al., 2015, Heijnes et al., 2018; Prain \& Tytler, 2012), programming (Louca \& Zacharia, 2012; Wilensky \& Reisman, 2006), or stop-motion animation (SMA) (Farrokhnia et al., 2020; Hoban \& Nielsen, 2012; Wilkerson-Jerde et al., 2015). The resulting scientific models can be static, such as pictures, diagrams, graphs, equations, or they can be dynamic, e.g., video, animation, simulation (Gilbert \& Justi, 2016). Ryoo and Linn (2012) found that dynamic visualizations were more effective than static illustrations to depict dynamic processes, such as chemical reactions during photosynthesis. In another example, in order to build a model about the marine ecosystem with complex species behavior, dynamic representations were more suitable than static ones (Papaevripidou et al., 2007). Chang et al. (2014) also found that Chemation, a drawing tool, supported the students in visualizing their understanding about a dynamic aspect of a chemical reaction, such as how atoms moved and broke chemical bonds, with ease. An adequate modeling tool should thus ideally support student-constructed dynamic models.

Currently, existing computer modeling tools, such as Stagecast Creator, SimSketch, and SiMSAM, have been employed in many educational studies on student-constructed dynamic models (Bollen \& Joolingen, 2013, Heijnes et al., 2018; Louca et al., 2011a, 2011b; Louca \& Zacharia, 2008; Wilkerson-Jerde et al., 2015; Wilkerson et al., 2018). Louca and Zacharia (2008) compared two programming-based tools, i.e., Stagecast Creator and Microworld Logo. StageCast employs a visual, agent-based modeling language whereas Microworld Logo is based on programming code. Where the first is quicker in creating the model, Louca et al. (2011a) noticed that the students employing Stagecast Creator to construct a model of accelerated motion engaged in unproductive modeling discourse. That is, during the modeling process, the students struggled to include a programming rule that could represent accelerated motion.

The use of the latter two modeling tools above requires some formal representation of the model. This may be a drawback, especially for younger students. Sins et al. (2005) suggested that novice modelers employ qualitative graphical models, not requiring formal coding. Bollen and Joolingen (2013) present a drawing-based modeling tool, SimSketch, which provides more informal ways of constructing models, with freehand drawings as input, and not requiring programming language. A study by van Joolingen et al., (2015) showed that SimSketch supported the students in creating a model of solar eclipses. In another study, Heijnes et al. (2018) found that, by using SimSketch to model evolutionary processes, the students engaged in complex reasoning, as long as a sufficient level of scaffolding was provided.

All modeling tools discussed above, however, require the specification of explicit rules, in the form of code or as visual representations. In this study, we look at a way of modeling without explicit specification of model rules: stopmotion animation (SMA). With the advance of computer technologies, it is possible for students to design a SMA themselves with relative ease. SMA is a form of animation created from a series of individual images, called frames. Like a common animation, SMA can be used to visualize events changing over time. The construction of a SMA involves two essential strategies: chunking and sequencing 
(Hoban \& Nielsen, 2010). For example, to animate a process, it has to be broken down into a number of single steps, called chunks, and each step is represented in one or a small number of frames. All frames are sequenced in such a way that each frame looks like an alteration of the previous one. Thus, when these frames are played back, they appear to display the process in a continuous way.

A recent literature study reports on the benefits of SMA (Farrokhnia et al., 2020). In another study, Nielsen and Hoban (2015) found that, after creating a SMA, pre-service teachers gained more understanding of the moon phases than before the animation construction. Also, learning through creating a SMA afforded students opportunities to generate discussion (Hoban \& Nielsen, 2014; Mills et al., 2019). Mills et al. (2019) noticed that the construction of a SMA engaged students in resolving conflicting ideas by generating dialogue with their teacher. Other studies highlighting SMA can contribute to students' mechanistic reasoning (Wilkerson et al., 2018; Wilkerson-Jerde et al., 2015).

\section{Reasoning Mechanistically with Stop-Motion Animation}

Explaining a phenomenon mechanistically means to provide an account of why and how the phenomenon can occur in terms of entities and activities of these entities. Apart from these two elements, Russ et al. (2008) extended this view by introducing seven elements of mechanistic reasoning in a hierarchy, representing the level of sophistication: (1) the target phenomenon, (2) setup conditions, (3) entities, (4) activities of entities, (5) properties of entities, (6) organization of entities and activity, and (7) chaining. Entities are elements or agents playing a role in producing a phenomenon. Activities are what entities do to come up with a phenomenon. For example, in the phenomenon above about a melting ice cube, water molecules are an entity. "Moving faster" is an activity of those entities. Chaining, as the highest level of mechanistic reasoning, is a causal structure that makes a claim about why and how a phenomenon can occur. This causal structure represents a specific condition that would occur if entities engaged in specific activities. For instance, in the phenomenon about a melting ice cube, the statement "the water molecules eventually separate, thus forming liquid water" indicates the presence of chaining.

Krist et al. (2019) argued that mechanistic reasoning required identifying relevant factors at a scale below the level of the observed phenomenon, e.g., unobservable entities. However, mechanistic explanations of physical phenomena do not always involve invisible factors, such as system levers (Bolger et al., 2012) and accelerated motion (Louca et al., 2011a, Louca et al., 2011b). In this study, we paid attention to the way students conceptualize their abstractions of these factors in terms of a concrete and an abstract level. Consider two objects: "a ball" and "a molecule." In this study, we consider both these entities to be of a concrete nature as both are in principle observable, albeit on a different scale level. Abstract entities include constructs that are not observable or theoretical, even in principle, such as force or a gravitational field. Only the consequences of their presence may be observable. For an entity "gravity," there may be an associated activity, "pull down."

As discussed above, several studies employed a SMA as a modeling tool to support science learning, but only a few studies focused on the development of mechanistic reasoning, e.g., Wilkerson-Jerde et al. (2015) and Wilkerson et al. (2018) who studied reasoning about the spread of "smell." Even though these studies clearly demonstrate the occurrence of mechanistic reasoning during the construction of an SMA, the way in which the construction of an SMA affects students' thinking has gone largely unnoticed. Farrokhnia et al. (2020) suggest further study to investigate students' thinking during the construction process of SMA. One way to uncover the effect of the construction of SMA on students' thinking is by examining students' reasoning behind the main processes in this construction process: chunking and sequencing. We contend that building sequential chunks lead students to think in terms of entities and the activities of entities. Other mechanistic elements may also be called upon to make a coherent sequence. This means that, by unveiling students' reasoning behind the process of chunking and sequencing, we can gain insight into how constructing SMA works in inducing students to think in mechanistic ways.

\section{Method}

\section{Study Context}

A qualitative case study was used for obtaining a better understanding of how and why students' reasoning occurred throughout the creation of a stop-motion animation (Creswell \& Poth, 2018; Yin, 2013). This study involved ten ninth-grade students (5 males and 5 females; $15-17$ years old) from an international secondary school located in a large city in the Netherlands. Before the students took part in the study, a letter of consent from their parents had been obtained.

\section{Modeling Tasks and Data Collection}

In this study, a task-based one-on-one interview approach was conducted in the students' school. The interview was recorded on camera and by voice recording. On-screen activities were recorded using Camtasia screen capture software. Finally, all the student-constructed animation artifacts were collected. The modeling task was performed 

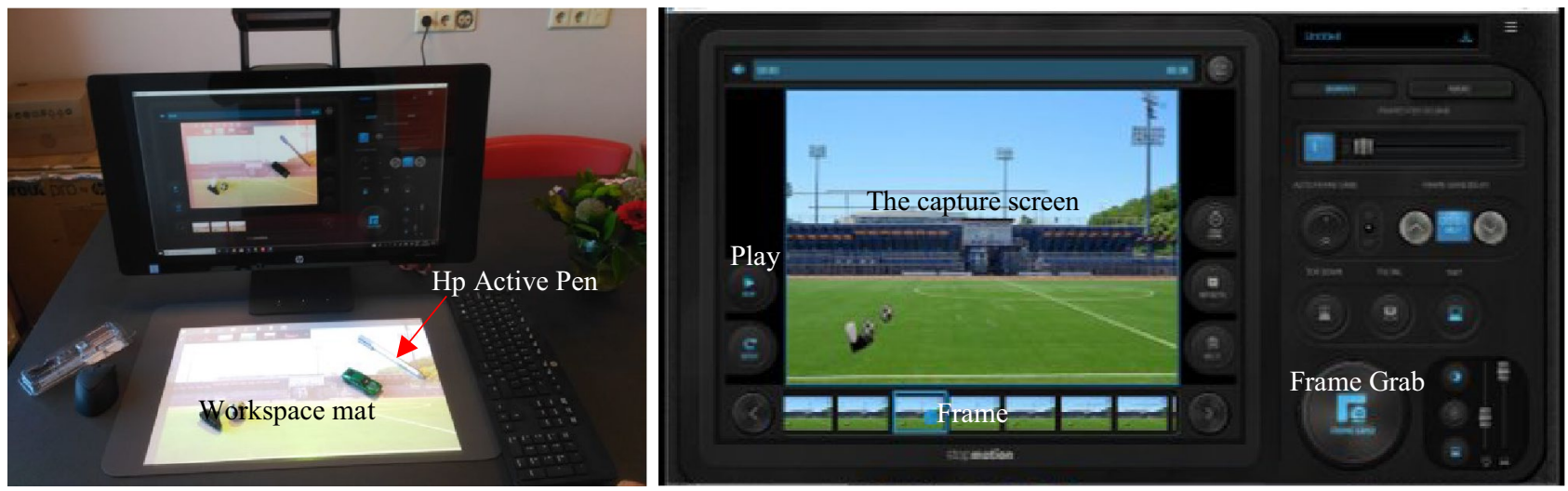

Fig. 1 Setup for creating stop-motion animations using a HP Sprout computer

in the built-in capture program of the HP Sprout computer (Fig. 1). The students modeled the motion of a ball after it was kicked by foot. This full task took $60 \mathrm{~min}$, and the students followed a three-stage procedure:

1. Introduction (10 minutes)

During the first stage, the students were introduced to the basic features of stop-motion animations, and the tools used to construct them (Fig. 1). The students practiced by creating a simple animation of a car moving in a straight line.

2. Creating the animation (15 minutes)

In the second stage, the students worked in creating the animation presenting motion of the ball. The construction of the animation begun by providing a schematic frame (frame 1 in Fig. 2) with the foot and the ball. The students were then asked to continue creating the next frame, e.g., frames 2 and 3 in Fig. 2. The students were not interrupted during the construction process. Guidance was provided only when they needed technical help.

3. Discussion (35 minutes)

To gain insight into the students' cognitive processes, a retrospective thinking-aloud was used (Ercikan et al., 2010; Ericsson \& Simon, 1998) requiring the stu- dents to verbalize their thought during the construction process. In prompting them to do so, the students were asked questions like as follows: (1) "In the third frame (Fig. 2), why do you think the ball moved here?" and (2) "How could the ball move here (Fig. 2; frame 3)?" Follow-up questions were based on concepts that came up. After the students had explained all frames, a video and a picture displaying the actual movement of a football being kicked by someone were presented. The students were then asked to compare their animation with both the video and the picture and to comment on any observations.

\section{Data Sources and Analysis}

The animations created by the participants and their utterances from audio-video recordings were transcribed and coded using the coding scheme for mechanistic reasoning developed by Russ et al. (2008). Table 1 shows this coding scheme and the example of coded utterances for our context. This coding process also included the students' level of abstraction, meaning how they used concrete-abstract concepts to conceptualize each element of mechanistic reasoning into either abstract or concrete. To validate this coding process, about $10 \%$ of
Fig. 2 The first three frames and frame 1 is a schematic frame

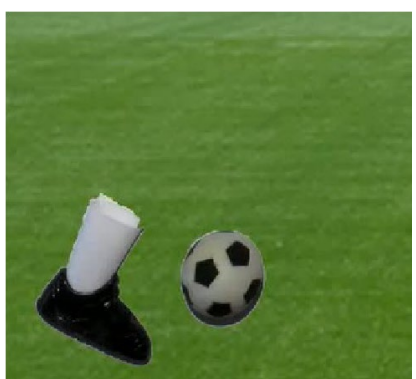

Frame 1

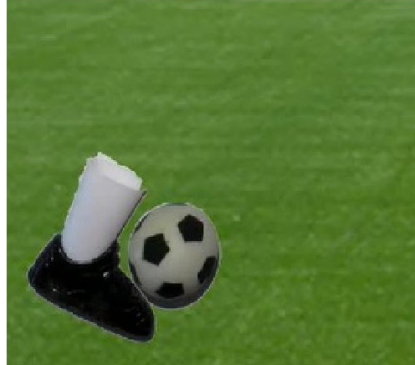

Frame 2

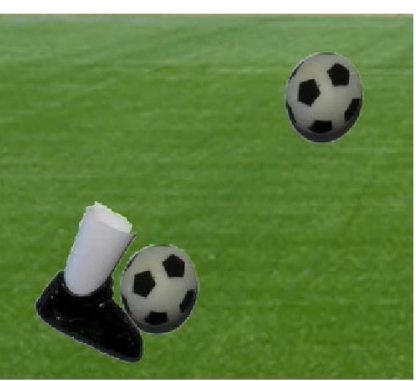

Frame 3 
Table 1 Coding scheme of mechanistic reasoning (adapted from Russ et al. (2008)) and the example of coded utterances

Mechanistic aspect
1. Target Phenomenon (TP)
We code the presence of this element in students' utterances when the
students describe a particular phenomenon without explaining how
and why this phenomenon occurs
2. Setup Condition (SC)
We code the students' statements as the setup condition when the
students describe a starting condition that must happen before the
particular event runs

3. Entity (E)

An entity is a causal agent that plays a crucial role in producing a phenomenon. We code for the presence of this element in the students' statements when they try to identify the agents that cause the phenomenon to happen. Those agents that are tangible or visible are classified as concrete concepts, whereas abstract agents are invisble or theoretical

4. Activity of entity (AI)

An activity is what entities engage in to produce a phenomenon. We code the students' statements as this aspect when the students identify what entities do to give rise to a phenomenon

\section{Property of Entity (PE)}

An entity has a general property. By having this property, the entity could do a specific activity. We code students' statement as property when the students identify any characteristic of an entity that is necessary for a certain activity

6. Organization of entity and activity (IOE)

For a phenomenon to happen sometimes requires a specific condition: spatial organization of entities or temporal organization of activities. We code the students' statements as this aspect when they describe where entities are located (spatial) or how long entities do the activities (temporal)

\section{Chaining (C)}

We marked the students' statements with chaining when their explanations present a cause-effect relationship. This relationship signifies a claim about what must have happened previously to bring about the current state of things (backward-chaining) or what will happen next given that certain entities and activities are present (forward-chaining). In this study, all students' chaining is classified as forward-chaining. Also, when students construct a chaining, they involve not only entities and activities but also other elements of mechanistic reasoning. For example, a chaining consists of entities, activities, and a setup condition

Because the students employ forward-chaining, their statements referring to the next condition are used to determine whether chaining is classified as concrete or abstract concepts. For example, "the ball goes up in a straight line, because you kick it with sort of an angle," the chaining is "the ball goes up in a straight line" and this chaining is concrete
Example of students' excerpts

Concrete:

"The ball goes up with a straight forward line"

Abstract:

"As the ball goes up, its energy is getting less"

Concrete:

"He kicks it with a sort of upward angle (in the first position)" this statement presents the way a football player kicks the ball in the first position to enable the ball to move up in a certain direction Abstract:

"When the foot is kicking the ball, it is transferring energy to the ball, and then this energy is used for the ball to go up"

This statement explains the way energy comes up, before the ball uses this energy to move up

Concrete entity: the foot, the earth

Abstract entity: energy, gravity

Concrete activity:

"The foot kicks the ball"

Activity is "kick the ball," and Entity is "the foot"

Abstract activity:

"The foot gives force to the ball"

Activity is "gives force," and Entity is "the foot"

Concrete property:

Air resistance is something that can be touched (property), so that "... because it needs to push all the particles of air out of your way"

Abstract property:

"it (the ball) still has forward momentum (property)"

Concrete:

"The ball has only kinetic energy, when the ball is on the ground" Abstract

"The ball can go up as long as the energy is stronger than gravity"

Concrete:

"Because you kick the ball up, so the ball goes up in a straight line" Abstract:

"As the ball goes up (with a change in the direction), it loses momentum." the coding was then checked by a second coder from the same institute. Interrater reliability (Cohen's kappa) was found to be 0.79 . Coded utterances were displayed in a graph, wherein one graph presented the students' reasoning about each phase of the ball motion, for example, the graph in Fig. 4. 


\section{Results}

\section{Model of the Ball Motion}

All students succeeded in creating an SMA representing the motion of the ball resembling a curved trajectory. For instance, Fig. 3 displays the animation created by student A. For analytical purposes, we divided the ball's motion into three sequential phases (as for example in Fig. 3b): (1) phase A, the initial movement (frames 1, 2, and 3); (2) phase B, when the ball starts to ascend slower, up to the point where it reaches maximum height (frames 3, 4, and 5); and (3) phase $\mathrm{C}$, describing the downward motion until the ball reaches the ground (frames $5,6,7$, and 8 ). Table 2 provides the characteristics of each phase extracted from all students' reasoning and an example of the students' statements describing these phases, together with concrete and abstract concepts.

\section{Mechanistic Reasoning as Demonstrated in the Reasoning about the Animations}

Figure 4 represents the combined utterances from all students' reasoning about the ball's motion. In general, reasoning about phase A mostly incorporated concrete concepts. Notably, the use of abstract reasoning became more frequent in phases B and C. Entities (element 3 ) and activities of these entities (element 4) were most prevalent in all phases. As shown in Fig. 4, all students did indeed display these two elements in all phases. All students were thus able to generate mechanistic reasoning. In phase A, all students conceived entities as concrete concepts, such as the foot and kicking, and few students invoked abstract entities, e.g., force. In subsequent phases, all students were able to exhibit abstract entities, such as momentum, gravity.

Chaining was prevalent in phases $\mathrm{A}$ and $\mathrm{B}$, but this almost disappeared in phase $\mathrm{C}$ (see Fig. 4). In addition, the abstraction of chaining and the total number of students reaching chaining differed in all phases. All students could reach chaining in phase $\mathrm{A}$, but in phase $\mathrm{C}$, only one student could do so. Those students were able to identify entities and were capable of assigning a plausible action to these entities to enable a particular movement of the ball to occur. In the following section, we examine the reasoning in each phase of the ball's motion. We chose two representative students: student A and student B. These two students are taken as being representative of a group of the students who employed abstract entities from the start (phase A) and the other students who only started using abstract entities from phase B onwards. Additionally, in phase C, student B exhibited chaining, whereas student A did not.
Fig. 3 The stop-motion animation representing the motion of the ball created by student A. a A series of eight frames depicting a sequence of moves of the ball; $\mathbf{b}$ drawings added by the student to the animation to explain it afterwards

$\mathbf{a}$

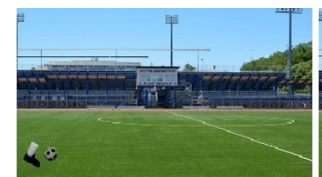

Frame 1

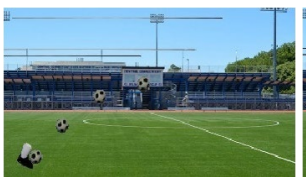

Frame 5

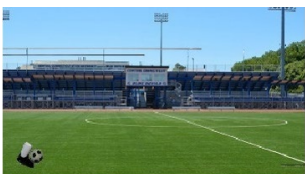

Frame 2

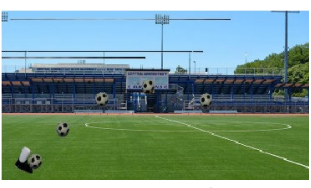

Frame 6

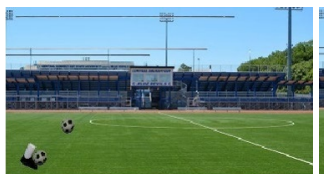

Frame 3

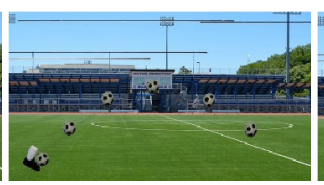

Frame 7

b

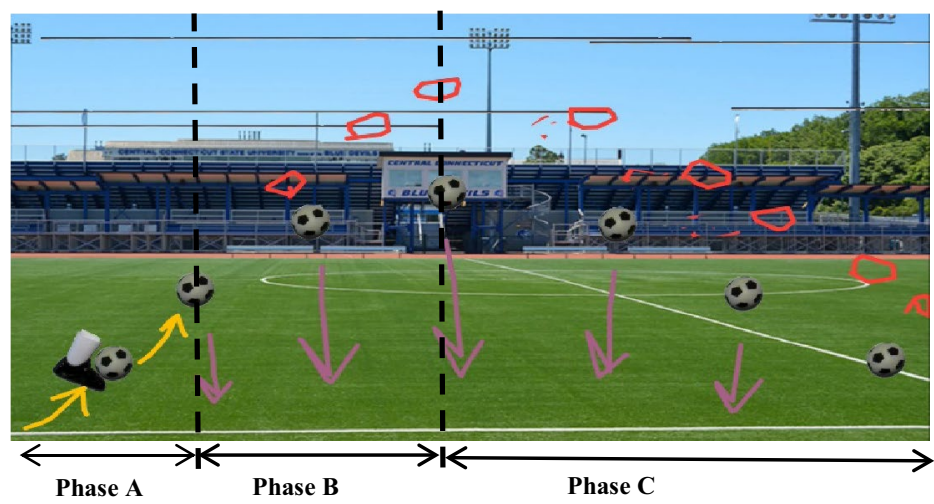

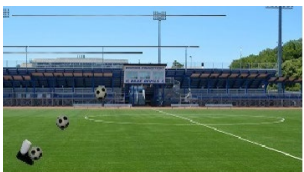

Frame 4

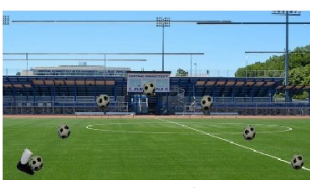

Frame 8 
Table 2 The characteristics of phases A, B, and C and the students' reasoning about these phases

\begin{tabular}{|c|c|c|}
\hline Phase & Characteristics & Example of quote \\
\hline Phase A & $\begin{array}{l}\text { This phase is the initial movement of the ball. The motion } \\
\text { immediately after the ball is kicked. This movement is only } \\
\text { influenced by the kicking. There is no effect of gravity on this } \\
\text { movement. Some students argued that as the ball goes up, the } \\
\text { slope is constant }\end{array}$ & $\begin{array}{l}\text { Concrete concepts: } \\
\text { "so you kick it, and it goes there (to the second position in straight } \\
\text { line)" } \\
\text { Abstract concepts: } \\
\text { "the person who is kicking the ball, he is giving like the force } \\
\text { to the ball [from the bottom], that makes the ball go higher (in } \\
\text { straight line)" }\end{array}$ \\
\hline Phase B & $\begin{array}{l}\text { This phase is indicated by a change in the slope or the ball starts } \\
\text { to change its direction as it goes up. This movement takes place } \\
\text { from the moment the slope changes until the ball reaches the } \\
\text { highest position. There is an effect of gravity on this movement }\end{array}$ & $\begin{array}{l}\text { Concrete concepts: } \\
\text { "when it (the ball) is on here ( } 4 \text { th position), and then it starts } \\
\text { decreasing (goes up with a change in direction)" } \\
\text { Abstract concepts: } \\
\text { "yes, because the gravity is like starting to. Because the force that } \\
\text { is applied makes the ball goes higher, and then gravity makes the } \\
\text { ball, like pull back to the ground, so it is here (moves up with a } \\
\text { change in direction)" }\end{array}$ \\
\hline Phase C & $\begin{array}{l}\text { This phase happens when the ball starts going down from the top } \\
\text { position until it reaches the ground }\end{array}$ & $\begin{array}{l}\text { Concrete concepts: } \\
\text { "this point, at the highest point, it is up all the way, and then it is } \\
\text { still in arch in going down (move down with curved line)" } \\
\text { Abstract concepts: } \\
\text { "because the gravity starts, hmm like, the force applied doesn't } \\
\text { enough to continue to go higher, and the gravity starts pulling } \\
\text { the object [the ball] back to the ground [goes down from the } \\
\text { top]" }\end{array}$ \\
\hline
\end{tabular}

\section{Phase A}

In phase A, the ball moves upwards, more or less in a straight line. To reason about this motion, the abstractions exhibited by students A and B differed (see Fig. 5). Figure 5 shows that student B only employed concrete concepts, whereas student A involved abstract concepts. Both demonstrated concrete chaining.

Student A used the first three frames (see Fig. 3a) to depict the ball moving upwards immediately after a kick. She stated that:
"... because the force is from the bottom [2nd frame; 1st position] ... the person who is kicking the ball, he [the foot] is giving like the force to the ball [Frame 1 and Frame 2], that makes the ball [to] go higher [Frame 3] ... The foot is kicking the ball like here, from the bottom [she draws a yellow arrow to represent an elevation angle; see Fig. 3] which makes the ball [to] go to this position [the second position, she draws a second yellow arrow, which links the first position to the second position, to represent the ball moving up in a straight line ]...".
Fig. 4 The total number of times each element of mechanistic reasoning together with concrete and abstract concepts is used by ten students to reason about the ball's motion in each phase

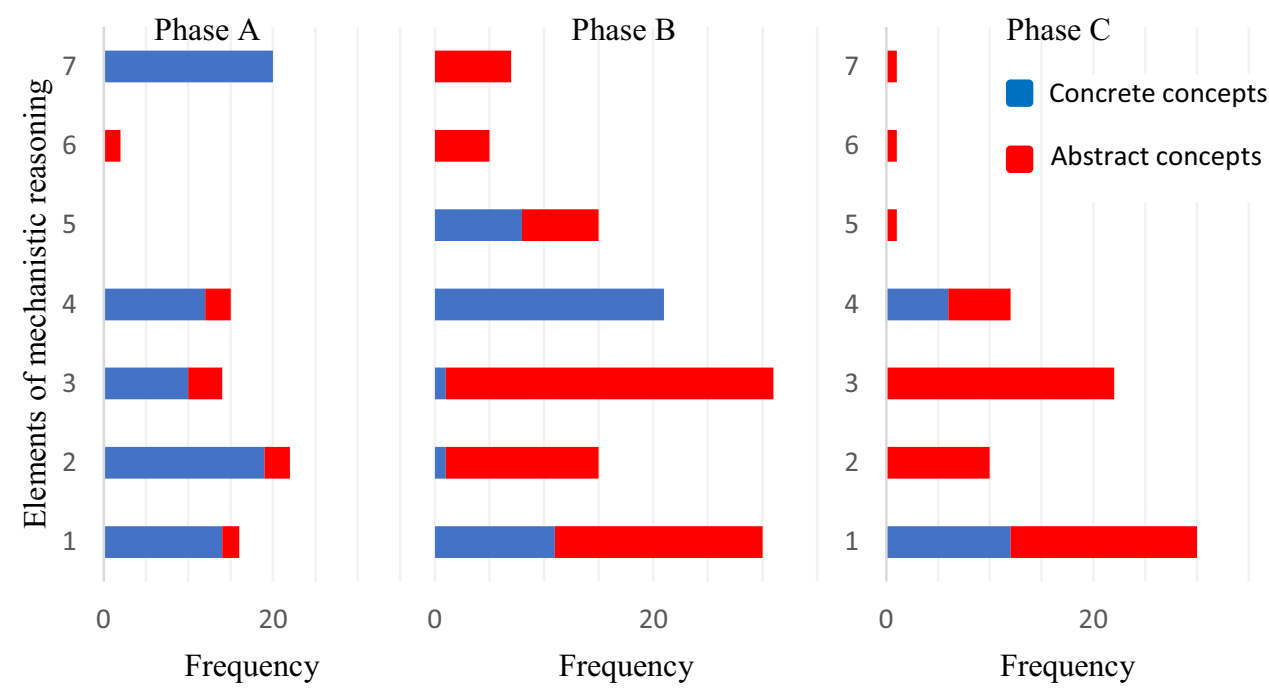


Fig. 5 Elements of mechanistic reasoning used by student $\mathbf{A}$ (left) and student $\mathbf{B}$ (right) to reason about phase $\mathrm{A}$

\section{Student A}

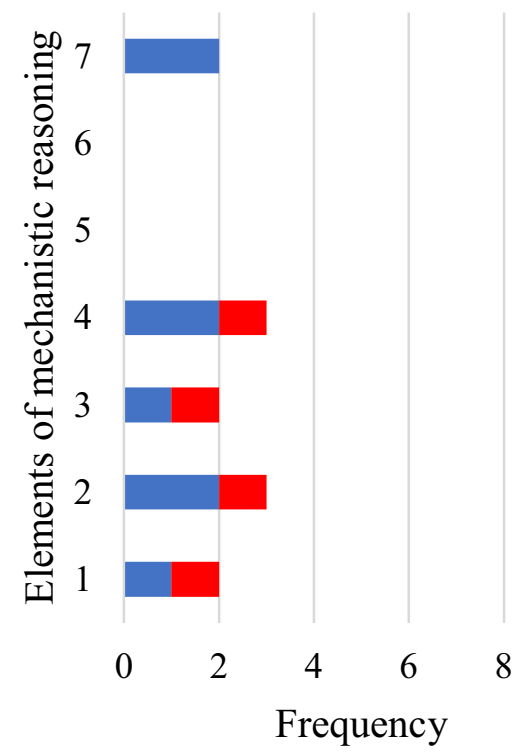

Student B

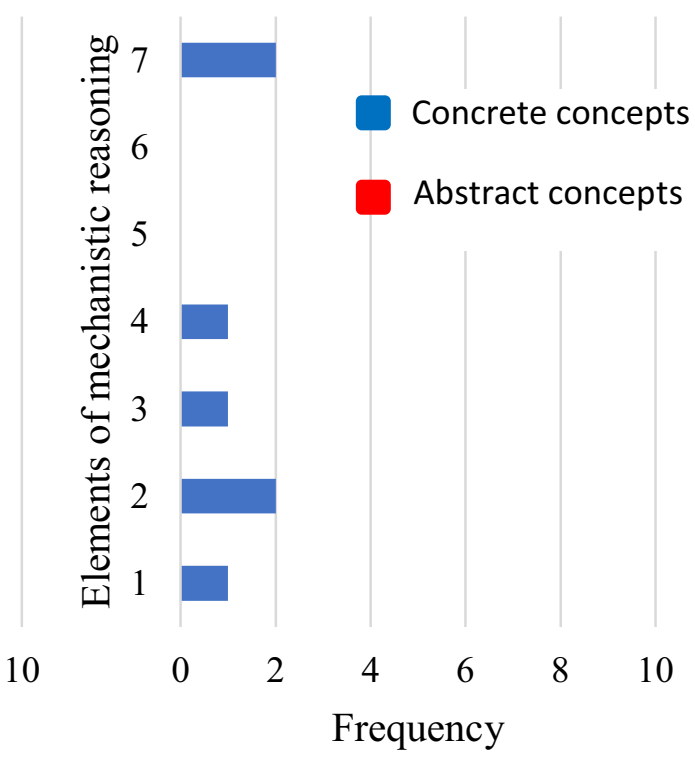

The excerpt above conveys student A who was able to explain the upward motion through generating a chaining involving concrete and abstract entities (element 3 ), concrete and abstract activities (element 4), and a concrete setup condition (element 2). She asserted that this motion could occur due to the abstract entity "force" that did "make the ball [to] go higher" (element 4; concrete). This entity existed because "the person" (element 3; concrete) who "was kicking the ball" (element 4; concrete) is "giving like the force to the ball" (element 4; abstract). Additionally, she also drew the first yellow arrow (see Fig. 3b) to represent a specific direction of kicking (element 2; concrete), indicating an elevation angle. Owing to this kicking, the ball could "go to this position [Frame 3]" in a straight line (element 7; concrete), and student $\mathrm{A}$ also drew the second yellow arrow to represent this motion.

Regarding the ball's motion in phase A (see Fig. 6), student B stated that:

“... because, I can see here [frame 1 and 2], that he kicks it with sort of upward angle, so I see sort of arch, forming... so you kick it [the ball], with sort of the angle [he points to a way of a kick representing the way the foot kicks the ball, namely an elevation angle], that makes it go that way [he draws a red line to represent the ball moving up to the second position in a straight line ]...".

Through concrete chaining (element 7), student B explained why and how the initial movement of the ball could go up in a straight line (see Fig. 6b). This chaining consisted of a concrete entity (element 3 ), a concrete activity (element 4 ), and a concrete setup condition (element 2). In frames 1 and 2, he identified a concrete entity, "he [the foot]," taking an action "kicks the ball" to cause the ball to move up. Additionally, in frame 2, he also added the particular way of kicking "with sort of the angle" (element 2; concrete), so "that makes it go that way [he draws a red line to represent the initial movement in straight line; see Fig. 6b]" (element 7; concrete).

\section{Phase B}

As shown in Fig. 7, the abstraction level used by students A and B to reason about phase B appears to be similar. Student $\mathrm{B}$ is now also employing abstract concepts:

“... after a certain time on air [in the second position; Frame 3], the ball starts to lose its momentum. And that [losing momentum] causes it [the ball] to slow down and a decrease in it [momentum]. hmm by slowing down, it [the ball] doesn't increase as much with its height [he draws a blue line to represent the ball which was moving up in straight line and then its direction changed]... when right from the kick off [Frame 1 and 2], it [the ball] will have a momentum, and it [momentum] will be lost, due to air resistance and gravity trying to pull it [the ball] back down. Since it [the ball] has to go, since it [the ball] is going up [frame 3 to frame 4], it [the ball] slows down, because it needs to push all the particles of air out of your way and also needs to fight the gravity which is very powerful of force...". 
Fig. 6 A stop-motion animation representing a model of the ball's motion constructed by student B. a A series of eight frames depicting a sequence of moves of the ball; $\mathbf{b}$ drawings added by the student to the animation during the explanations a

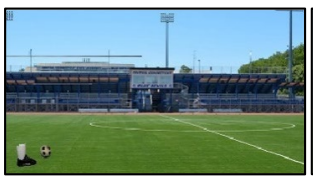

Frame 1

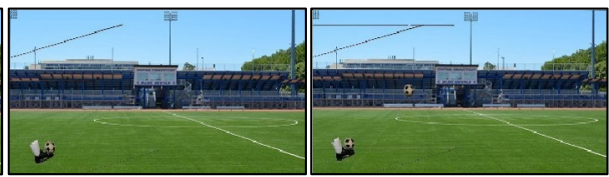

Frame 2

Frame 3

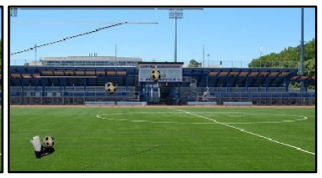

Frame 4

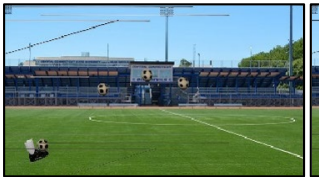

Frame 5

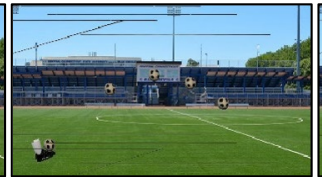

Frame 6

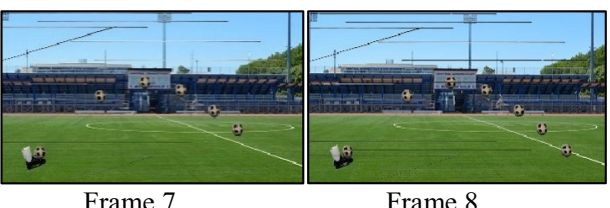

Frame 8

b

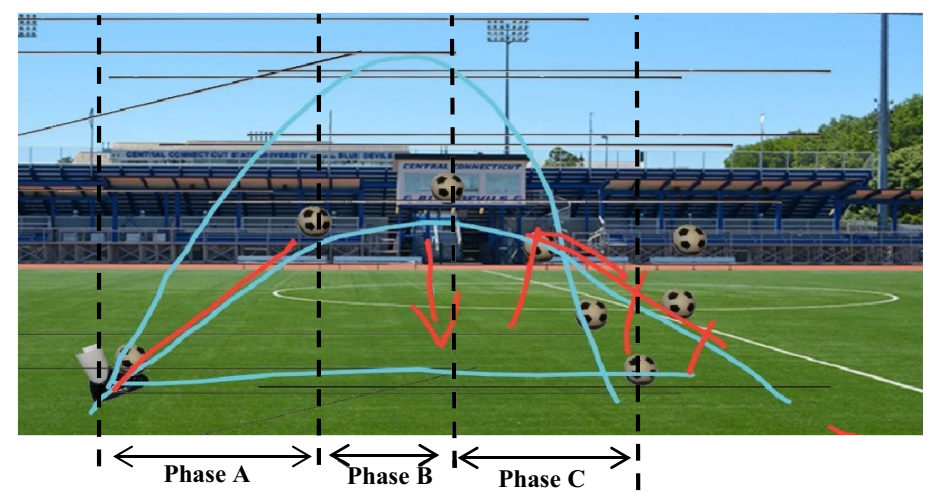

Moreover, student B was able to use abstract chaining to describe the reason for the change in the direction. Through chaining, he asserted that the abstract entities, i.e., momentum, gravity, and air resistance, played a crucial role in changing the direction. He argued that momentum arising from "right from the kick off" (element 2; abstract) enabled the ball to go up (element 4; concrete). He also identified the activity that gravity engaged in "trying to pull the ball down" (element
Fig. 7 Elements of mechanistic reasoning used by student $\mathbf{A}$ (left) and student $\mathbf{B}$ (right) to reason about phase $\mathrm{B}$

\section{Student A}

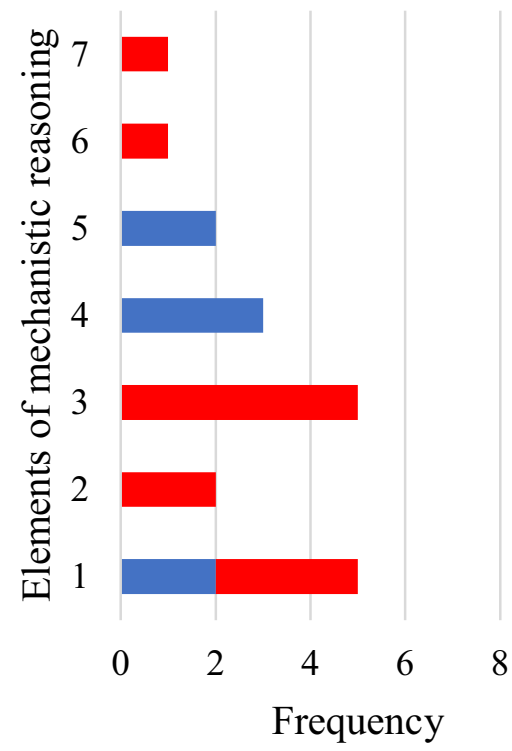

Student B

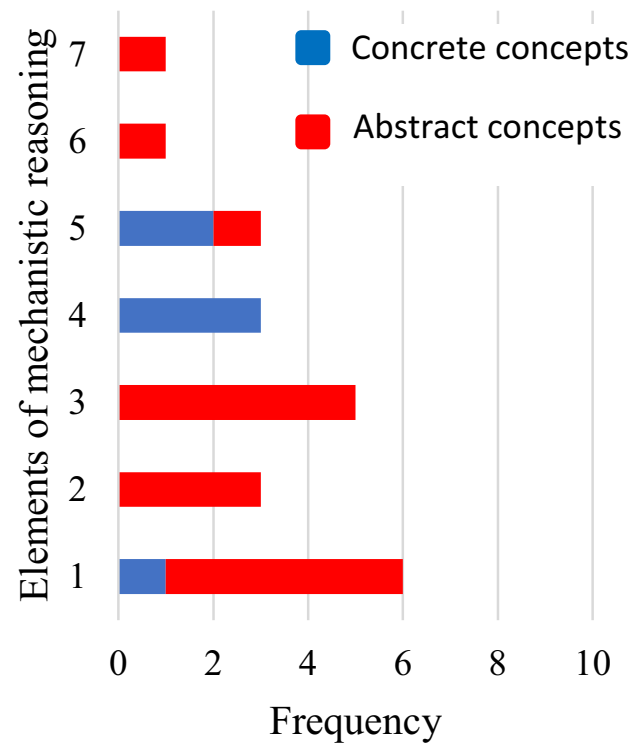


4; concrete). Additionally, he considered air resistance to be something that could be touched (element 5; concrete). With this general property of air resistance, this entity could behave and interact with other concrete entities, that is, along upward movement the ball "needs to push all the particles of air out of your way" (element 4; concrete). Additionally, he also contended that an activity of both air resistance and gravity was taking place over the upward movement (element 6; abstract): "also needs to fight the gravity which is very powerful of force." Therefore, as the ball went up, the ball's direction changed, because "the ball starts to lose its momentum, that (losing momentum) causes it (the ball) to slow down and decrease in it. Hmm by slowing down, it (the ball) doesn't increase as much with its height" (element 7; abstract).

\section{Phase C}

Figure 8 shows that, in phase $\mathrm{C}$, student $\mathrm{B}$ used chaining whereas student A did not. Student A constructed frames 5, 6, 7, and 8 (see Fig. 3a) to represent this phase. When explaining the way the ball moved down, student A began by arguing from a starting condition in the top position (frame 5) that the ball did not go up anymore. She stated that "because ... the force applied isn't enough to continue to go higher, ... the force gets less, and gravity is more strong or more powerful ..." (element 2; abstract). She then pointed out the reason why the ball could go down. She argued that:

“...because ... the gravity starts pulling the object

[the ball] back to the ground [from the top position]

... the ball gets faster, which increases its kinetic

energy. Also, potential energy decreases ....”.
Student A contended that the ball could go down due to gravity (element 3; abstract) taking an action, "pull the ball" (element 4; concrete). Due to a pull by gravity, the ball "gets faster which increases its kinetic energy, also potential energy decreases" as the ball went down. However, she did not explain the reason why the pull of gravity caused the ball to move faster and caused an increase in kinetic energy. In addition, she was unable to explain the reason why the ball could reach the specific position during the downward movement (as shown in Fig. 3b). Hence, her statements did not display chaining.

Figure 6 shows student B's explanation, that started with demonstrating the condition of the ball in the top position (frame 4) allowing the ball not to go up anymore. He stated that "because it [the ball] needs kinetic energy to go up (frame 4). And since it [the ball] ran out (moving up), it [the ball] almost uses its kinetic energy ... It [the ball] can't go up anymore, because it [the ball] needs more kinetic energy to do that..." (element 2; abstract).

Student B then described why the ball could reach the specific position as the ball went down (frames 5, 6, 7, and 8). He stated that:

"... so then it [the ball] reaches a peak [the top position; Frame 6], ... and then falling ... because now it [the ball] is working with gravity ... because this [gravity] wants to pull it [the ball] down [he points to the red arrow representing the work of gravity pulling the ball down; Frame 6, 7, and 8]. But it [the ball] still has forward momentum ... It [the ball] can't go forward straight, because it [the ball] still has to fight gravity, but it [the ball] is working with gravity, but it
Fig. 8 Elements of mechanistic reasoning used by student $\mathbf{A}$ (left) and student $\mathbf{B}$ (right) to reason about phase $\mathrm{C}$

\section{Student A}

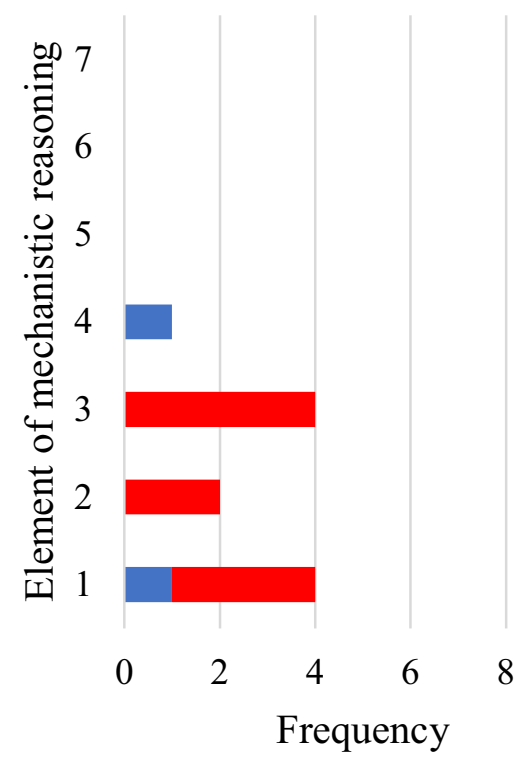

Student B

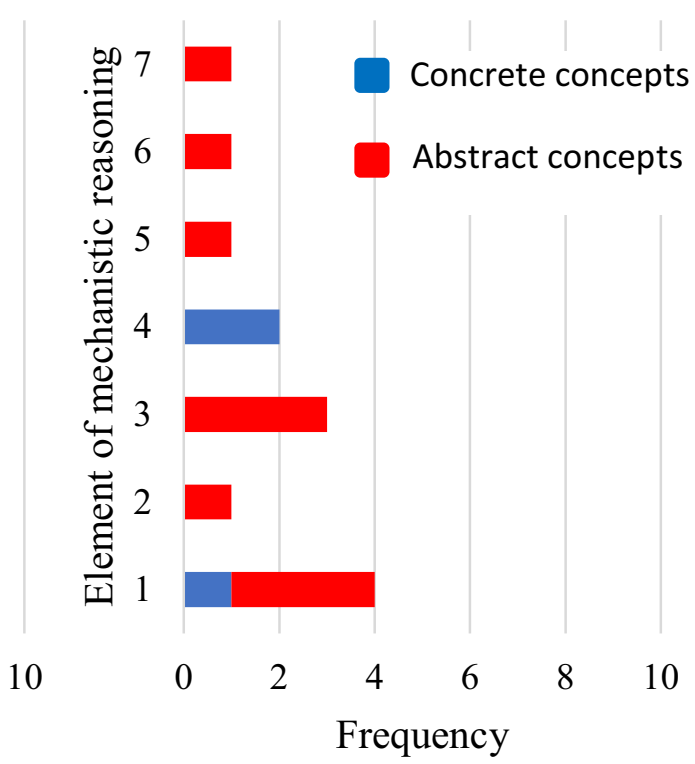


[the ball] still has some residual forward momentum. so when you do with that, it is sort of slope down, and angle [the ball moves down gradually], instead of dropping down immediately [he gestures to each position to depict the gradual downward movement] ...".

Student B contended that two abstract entities "momentum" and "gravity" played a role in preventing the ball falling straight down. During downward movement, gravity "pulls the ball down" (element 4; concrete), and the ball has "some residual forward momentum" (element 5; abstract) maintaining horizontal velocity "instead of dropping down immediately" (element 4; concrete). As a result, the ball moved down gradually "when you do with that, it is sort of slope down, and angle" (element 7; abstract).

In sum, even though students A and B started with a different abstraction of reasoning, both exhibited concrete chaining. Both students also used abstract chaining in phase B. However, student B was the only one who did so in phase C. Moreover, there appeared to be an increase in student B's understanding of the motion. In particular, his conception of entity evolved toward a more scientifically correct use of the concept. In phase B, student B identified momentum as an entity to enable the ball to move up. In phase $\mathrm{C}$, he conceptualized momentum as a vector "forward momentum."

\section{Discussion and Conclusions}

The main goal of this study was to investigate how engaging students in constructing SMA could induce mechanistic reasoning. The first research question was "To what extent are 9th grade students able to model a phenomenon in classical mechanics using stop-motion animation?" We found that all students were able to sequence frames to model a ball motion resembling a curved trajectory. Three distinct phases could be distinguished in each model: the initial upward movement (phase A), the change in direction (phase
B), and the downward movement (phase C). Constructing the model using the stop-motion animation required the students to visualize the moment-by-moment motion of the ball, and these moments are arranged in order (chunking and sequencing). It was found that the creation of the first moment (phase A) was mostly attributed to a visible agent "the foot." In the subsequent moments, most of the students started to think about invisible agents. Moreover, the last two moments triggered students to think deeply with content, in particular the usage of abstract concepts.

The second research question was "To what extent do the students use mechanistic reasoning while discussing their stop-motion animations?" The stop-motion animation as a means to model the ball motion supported all students in building mechanistic reasoning, as it becomes clear from the presence of entities and activities in all phases. We attribute these to chunking and sequencing to model the ball motion. In Fig. 9, we represent how students built mechanistic reasoning through chunking and sequencing. When sequencing the frames, the students needed to identify relevant entities. At the same time, they also thought about plausible activities of those entities to make the plausible move to the next chunk (the next frame). Most of the students incorporated the other mechanistic elements to enable the next move to occur. For instance, in frames 1 and 2, student A thought about the specific way an entity, "the foot," kicked the ball (as an activity of the foot) to enable the ball moving up to the second position in a straight line (frame 3 ). These findings are in line with previous studies, e.g., Wilkerson-Jerde et al. (2015); Wilkerson et al. (2018), who noted that the animation construction process itself played an important role in stimulating students to identify the entity "fog" and how this entity behaved to give rise to evaporation.

Analysis of the data revealed that the construction of a stop-motion animation afforded opportunities for the students to engage deeply with content. This can be seen by the fact that the students' reasoning becomes more abstract in subsequent phases. In particular, phase B elicited abstract
Fig. 9 A way students build mechanistic reasoning through chunking and sequencing

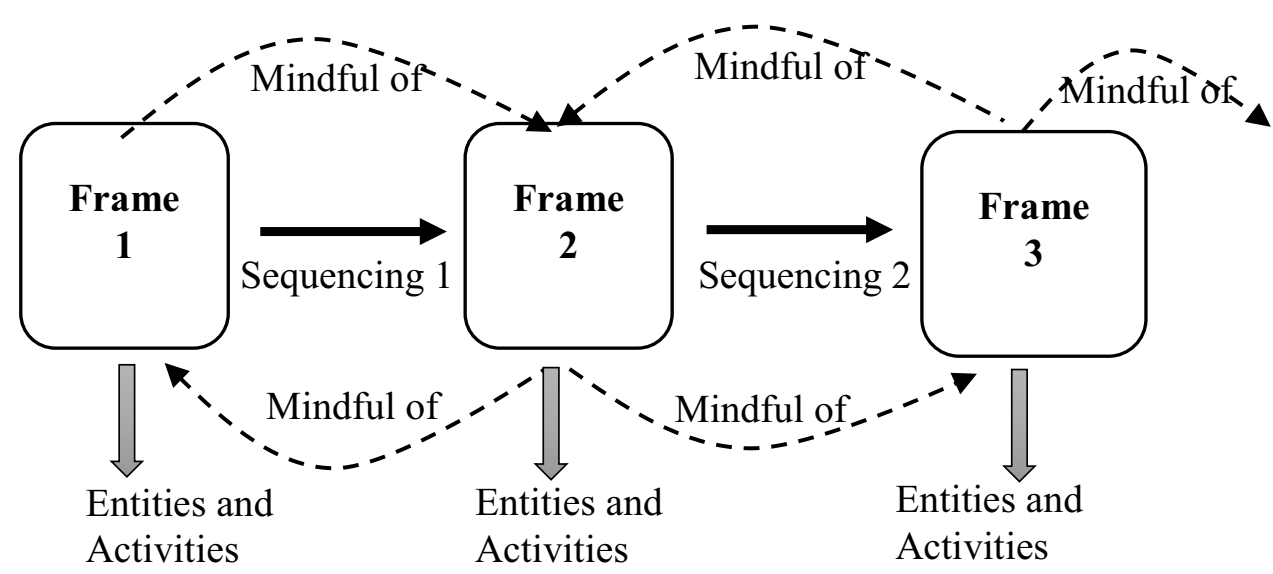


reasoning most explicitly: there was a considerable increase in the number of abstract entities used. Moreover, even though most of the students did not start using those entities at the beginning (phase A), they did so in phase B. The notion that the trajectory will, at some point, has to flatten while the ball is in no way visibly connected to a changing agent is what appears to elicit the use of abstract entities. In this explanation, intangible concepts are needed, whereas the straight-line movement in phase A does not require these concepts in principle, since nothing changes in the direction of the movement. The students thus introduce concepts, such as momentum, air resistance, and gravity, in phase B to explain the change in the direction.

The results of the analyses showed that the students who engaged in chaining were capable of gaining a deeper understanding of concepts. For example, student B argued, using chaining, that for each position of the ball, the motion was the resultant of two vector entities, i.e., gravity and momentum, so that the ball gradually moved down. On the other hand, student A appeared to be unable to exhibit chaining in phase C. She only argued that, due to gravity pulling down, the ball moved down. However, she was not capable of explaining the reason why a pull by gravity prevented the ball from falling down in a straight line.

Student A's failure to reason with chaining was attributed to lack of either the presence of a property of entities (element 5 ) or an organization of these entities (element 6). Russ et al. (2008) argued that students who did not specify a relevant property of the entities seemed to use a scientific knowledge that they did not understand. Thus, if student A used entities that made sense to her, we might expect that she could identify a relevant property of the entity. As a consequence, she might be then able to assign the specific activities of the entity that enabled the specific trajectory of the ball to happen or an increase in both speed and kinetic energy to occur.

\section{Implication}

The current study provides a first insight in how SMA can induce mechanistic reasoning, especially chaining and abstract reasoning in lower secondary students. In future studies, this will need to be explored further, for instance, how thinking about more aspects of mechanistic reasoning can be supported, such as setup condition, properties of entities, and organization of entities. Additionally, we propose to conduct studies that focus on the differences in terms of elicited mechanistic reasoning between SMA on the one hand, and other forms of representation (e.g., simple drawing and thinking aloud about the drawings) on the other. Also, the studies should extend to other domains (e.g., multi-agent systems) and student groups (e.g., from primary school to university). A quasi-experimental design to compare the quality of learning science through a stop-motion animation to the other modeling approaches would also be very useful (Farrokhnia et al., 2020). This comparison could also include expert-generated animations to investigate whether students' reasoning strategies for learning science with such models differ.

Supplementary Information The online version contains supplementary material available at https://doi.org/10.1007/s10956-021-09918-z.

Acknowledgements The authors would like to thank Ylva Muilwijk, the physics teacher in the Rotterdam International Secondary School, for collaboration in this project. We wish to thank Michiel van Harskamp and Nathalie Kuijpers for valuable feedback on earlier version of this article. We also thank Wouter Koning for being the second coder (rater), and volunteers for participating in the pilot study.

Funding This project is supported by IsDB 4in1 Project-DIKTI Indonesia and Utrecht University $\mathrm{PhD}$ research fund.

\section{Declarations}

Informed Consent An informed consent was obtained from all participants or anonymous data collection was used.

Conflict of Interest The authors declare no competing interests.

Open Access This article is licensed under a Creative Commons Attribution 4.0 International License, which permits use, sharing, adaptation, distribution and reproduction in any medium or format, as long as you give appropriate credit to the original author(s) and the source, provide a link to the Creative Commons licence, and indicate if changes were made. The images or other third party material in this article are included in the article's Creative Commons licence, unless indicated otherwise in a credit line to the material. If material is not included in the article's Creative Commons licence and your intended use is not permitted by statutory regulation or exceeds the permitted use, you will need to obtain permission directly from the copyright holder. To view a copy of this licence, visit http://creativecommons.org/licenses/by/4.0/.

\section{References}

Ainsworth, S., Prain, V., \& Tytler, R. (2011). Drawing to learn in science. Science, 333(6046), 1096-1097. https://doi.org/10.1126/ science. 1204153

Bolger, M. S., Kobiela, M., Weinberg, P. J., \& Lehrer, R. (2012). Children's mechanistic reasoning. Cognition and Instruction, 30(2), 170-206. https://doi.org/10.1080/07370008.2012.661815

Bollen, L., \& van Joolingen, W. R. (2013). SimSketch: Multiagent simulations based on learner-created sketches for early science education. IEEE transactions on learning technologies, 6(3), 208216. https://doi.org/10.1109/TLT.2013.9

Braaten, M., \& Windschitl, M. (2011). Working toward a stronger conceptualization of scientific explanation for science education. Science Education, 95(4), 639-669. https://doi.org/10.1002/sce. 20449

Chang, H. Y., Quintana, C., \& Krajcik, J. (2014). Using drawing technology to assess students' visualizations of chemical reaction processes. Journal of Science Education and Technology, 23(3), 355-369. https://doi.org/10.1007/s10956-013-9468-2. 
Creswell, J. W., \& Poth, C. N. (2018). Qualitative inquiry research design: Choosing among five approaches (fourth edition). Sage Publications.

de Andrade, V., Freire, S., \& Baptista, M. (2019). Constructing scientific explanations: a system of analysis for students' explanations. Research in Science Education, 49(3), 787-807. https://doi.org/ 10.1007/s11165-017-9648-9

Ercikan, K., Arim, R., Law, D., Domene, J., Gagnon, F., \& Lacroix, S. (2010). Application of think aloud protocols for examining and confirming sources of differential item functioning identified by expert reviews. Educational Measurement: Issues and Practice, 29(2), 24-35. https://doi.org/10.1111/j.1745-3992.2010.00173.x

Ericsson, K. A., \& Simon, H. A. (1998). How to study thinking in everyday life: Contrasting think-aloud protocols with descriptions and explanations of thinking. Mind, Culture, and Activity, 5(3), 178-186. https://doi.org/10.1207/s15327884mca0503_3

Farrokhnia, M., Meulenbroeks, R. F., \& van Joolingen, W. R. (2020). Student-generated stop-motion animation in science classes: A systematic literature review. Journal of Science Education and Technology, 29(6), 797-812. https://doi.org/10.1007/ s10956-020-09857-1

Gilbert, J. K., \& Justi, R. (2016). The contribution of visualisation to modelling-based teaching. In: Modelling-based Teaching in Science Education. Models and Modeling in Science Education (vol 9, pp. 121-148). Springer, Cham. https://doi.org/10.1007/ 978-3-319-29039-3_7

Haskel-Ittah, M., Duncan, R. G., Vázquez-Ben, L., \& Yarden, A. (2020). Reasoning about genetic mechanisms: Affordances and constraints for learning. Journal of Research in Science Teaching, 57(3), 342-367. https://doi.org/10.1002/tea.21595

Heijnes, D., van Joolingen, W. R., \& Leenaars, F. (2018). Stimulating scientific reasoning with drawing-based modeling. Journal of Science Education and Technology, 27(1), 45-56. https://doi.org/10. 1007/s10956-017-9707-z

Hoban, G., \& Nielsen, W. (2010). The 5 Rs: A new teaching approach to encourage slowmations (student-generated animations) of science concepts. Teaching Science, 56(3), 33-38.

Hoban, G., \& Nielsen, W. (2012). Using "slowmation" to enable preservice primary teachers to create multimodal representations of science concepts. Research in Science Education, 42(6), 1101-1119. https://doi.org/10.1007/s11165-011-9236-3

Hoban, G., \& Nielsen, W. (2014). Creating a narrated stop-motion animation to explain science: The affordances of "slowmation" for generating discussion. Teaching and Teacher Education, 42, 68-78. https://doi.org/10.1016/j.tate.2014.04.007

Krist, C., Schwarz, C. V., \& Reiser, B. J. (2019). Identifying essential epistemic heuristics for guiding mechanistic reasoning in science learning. Journal of the Learning Sciences, 28(2), 160-205. https://doi.org/10.1080/10508406.2018.1510404

Louca, L. T., \& Zacharia, Z. C. (2008). The use of computer-based programming environments as computer modelling tools in early science education: The cases of textual and graphical program languages. International Journal of Science Education, 30(3), 287-323. https://doi.org/10.1080/09500690601188620

Louca, L. T., \& Zacharia, Z. C. (2012). Modeling-based learning in science education: Cognitive, metacognitive, social. Material and Epistemological Contributions. Educational Review, 64(4), 471-492. https://doi.org/10.1080/00131911.2011.628748

Louca, L. T., Zacharia, Z. C., \& Constantinou, C. P. (2011a). In quest of productive modeling-based learning discourse in elementary school science. Journal of Research in Science Teaching, 48(8), 919-951. http://doi.wiley.com/10.1002/tea.20435

Louca, L. T., Zacharia, Z., Michael, M., \& Constantinou, C. (2011b). Objects, entities, behaviors, and interactions: A typology of student-constructed computer-based models of physical phenomena.
Journal of Educational Computing Research, 44(2), 173-201. https://doi.org/10.2190/EC.44.2.c

Machamer, P., Darden, L., \& Craver, C. F. (2000). Thinking about mechanisms. Philosophy of Science, 67(1), 1-25. https://doi.org/ $10.1086 / 392759$

Mills, R., Tomas, L., \& Lewthwaite, B. (2019) The impact of studentconstructed animation on middle school students' learning about plate tectonics. Journal of Science Education and Technology, 28(2), 165-177. https://doi.org/10.1007/s10956-018-9755-z

Nielsen, W., \& Hoban, G. (2015). Designing a digital teaching resource to explain phases of the moon: A case study of preservice elementary teachers making a slowmation. Journal of Research in Science Teaching, 52(9), 1207-1233. https://doi.org/10.1002/tea.21242

Papaevripidou, M., Constantinou, C. P., \& Zacharia, Z. C. (2007). Modeling complex marine ecosystems: an investigation of two teaching approaches with fifth graders. Journal of Computer Assisted Learning, 23(2), 145-157. https://doi.org/10.1111/j.1365-2729. 2006.00217.x

Prain, V., \& Tytler, R. (2012). Learning through constructing representations in science: A framework of representational construction affordances. International Journal of Science Education, 34(17), 2751-2773. https://doi.org/10.1080/09500693.2011.626462

Russ, R. S., Scherr, R. E., Hammer, D., \& Mikeska, J. (2008). Recognizing mechanistic reasoning in student scientific inquiry: A framework for discourse analysis developed from philosophy of science. Science Education, 92(3), 499-525. https://doi.org/10. $1002 /$ sce. 20264

Ryoo, K., \& Linn, M. C. (2012). Can dynamic visualizations improve middle school students' understanding of energy in photosynthesis? Journal of Research in Science Teaching, 49(2), 218-243. https://doi.org/10.1002/tea.21003

Schwarz, C. V., Ke, L., Lee, M., \& Rosenberg, J. (2014). Developing mechanistic model-based explanations of phenomena: Case studies of two fifth grade students' epistemologies in practice over time. Proceedings of International Conference of the Learning Sciences, ICLS, 1(June), 182-189.

Sins, P. H., Savelsbergh, E. R., \& van Joolingen, W. R. (2005). The difficult process of scientific modelling: An analysis of novices' reasoning during computer-based modelling. International Journal of Science Education, 27(14), 1695-1721. https://doi.org/10. 1080/09500690500206408

Southard, K., Wince, T., Meddleton, S., \& Bolger, M. S. (2016). Features of knowledge building in biology: Understanding undergraduate students' ideas about molecular mechanisms. $C B E$ Life Sciences Education, 15(1), ar7. https://doi.org/10.1187/cbe. 15-05-0114

Speth, E. B., Shaw, N., Momsen, J., Reinagel, A., Le, P., Taqieddin, R., \& Long, T. (2014). Introductory biology students' conceptual models and explanations of the origin of variation. CBE Life Sciences Education, 13(3), 529-539. https://doi.org/10.1187/cbe. 14-02-0020

Talanquer, V. (2010). Exploring dominant types of explanations built by general chemistry students. International Journal of Science Education, 32(18), 2393-2412. https://doi.org/10. 1080/09500690903369662

Talanquer, V. (2018). Exploring mechanistic reasoning in chemistry. In J. Yeo, T. Teo, \& KS. Tang (Eds), Science Education Research and Practice in Asia-Pacific and Beyond (pp. 39-52). Springer Singapore. https://doi.org/10.1007/978-981-10-5149-4_3

van Joolingen, W. R., Aukes, A. V., Gijlers, H., \& Bollen, L. (2015). Understanding elementary astronomy by making drawing-based models. Journal of Science Education and Technology, 24(2-3), 256-264. https://doi.org/10.1007/s10956-014-9540-6

Visintainer, T., \& Linn, M. (2015). Sixth-grade students' progress in understanding the mechanisms of global climate change. 
Journal of Science Education and Technology, 24(2-3), 287310. https://doi.org/10.1007/s10956-014-9538-0

Wilensky, U., \& Reisman, K. (2006). Thinking like a wolf, a sheep, or a firefly: Learning biology through constructing and testing computational theories - An embodied modeling approach. Cognition and Instruction, 24(2), 171-209. https://doi.org/10.1207/ s1532690xci2402_1

Wilkerson-Jerde, M. H., Gravel, B. E., \& Macrander, C. A. (2015). Exploring shifts in middle school learners' modeling activity while generating drawings, animations, and computational simulations of molecular diffusion. Journal of Science Education and Technology, 24(2-3), 396-415. https://doi.org/10.1007/ s10956-014-9497-5
Wilkerson, M. H., Shareff, R., Laina, V., \& Gravel, B. (2018). Epistemic gameplay and discovery in computational model-based inquiry activities. Instructional Science, 46, 35-60. https://doi. org/10.1007/s11251-017-9430-4

Yin, R. K. (2013). Case study research: Design and methods (Fifth Edition). Sage Publications.

Publisher's Note Springer Nature remains neutral with regard to jurisdictional claims in published maps and institutional affiliations. 